\title{
Introduction to the research topic on standard brain atlases
}

\section{Randolf Menzel*}

Neurobiology Unit, Freie Universiät Berlin, Berlin, Germany

${ }^{*}$ Correspondence: menzel@neurobiologie.fu-berlin.de

Understanding neural function is based on knowledge about the wiring of the brain (Ramon y Cajal, 1897). Neuroanatomy has made an enormous leap in recent years with the advent of confocal and multi-photon microscopy, powerful graphic computers, cheap digital storage material, and the internet. Several initiatives have been successfully created aiming to convert neuroanatomy into a quantitative science. Whole brains or parts of them are documented in digital data sets that are accessible via the internet and allow for an ever-increasing collection of well-organized and carefully documented anatomical data.

Challenged by the need to integrate the rapidly growing data in neuroscience, digital brain atlases have become an important tool serving as databases for neural substrates with full 3D spatial information. The intension is to provide common frameworks into which neuroanatomical and physiological data can be registered and spatially related. Registration of neuroanatomical data in an atlas allows accumulating structural data from different brains of the same animal species into structural neural networks as well as identifying locations and distributions of synaptic interactions in the network.

Due to large differences in brain size, atlases differ in resolution and completeness. Invertebrate ganglia and brains are small enough to be analyzed by light microscopy as a whole on the level of single neurons and clusters of synaptic connections. The concept of the identified neuron is a powerful guide in the understanding of neural function in invertebrates requiring the identification, localization, and characterization of each neuron in the respective ganglion and brain. A neuron can be classified as identified on the single cell level when its Gestalt, functional properties and cellular components as compared to other neurons is found to be unique. Although we are far from this goal for most invertebrates (not even mentioning vertebrates) the tools are available as one can learn from the data on the nervous system of the nematode worm Caenorhabditis elegans (Hall and Russell, 1991), and the insect Drosophila (Chiang et al., 2011). In a long run the working of nervous systems will be understood only if the networks of such neurons are anatomically and functionally characterized, a goal that has been reached already for a small invertebrate ganglion, the stomatogastric ganglion of Decapoda crustaceans (Nusbaum and Beenhakker, 2002). Functional imaging at high resolution speeds up the process of network characterization, an experimental approach that will be productive only if the structure of the network is known and accessible in form of a $3 \mathrm{D}$ atlas.

The contributions to this special issue focus on optical methods (confocal, multiple photon, and ultra microscopy) for the analysis of neural structures aiming to construct a virtual 3D environment, the brain atlas. This atlas compiles the anatomical structures, and allows for the registration of neurons and their networks down to the level tight appositions between neighboring neurons and synaptic complexes. Electron microscopical analyses will be the next step, a step that requires an atlas as a $3 \mathrm{D}$ guide.

The first section (Digital Brain Atlases, Creation, Composition, Use, and Maintenance) addresses a range of questions related to the processes of constructing standardized brain atlases, how they are used and what kind of problems we face when maintaining them. As pointed out in the article by Kei Ito the maintenance of the large data sets of a brain atlas is a challenging task for which the structure of our laborites and research agencies are not well prepared. He argues in favor of a new form of researcher, the biocurator, who receives recognitions by the science community to provide access to well-organized and world wide usable data of a brain atlas. Indeed this is an enormously important move as everybody knows who has failed in getting research grants approved that aim to establish and maintain a brain atlas for the international science community. Kei Ito points also to another problem which we need to take seriously. "It is ironical that, whereas we can read and cite anatomical books and papers written even more than 150 years ago to access the knowledge and thoughts of our predecessors, most of the effort we are putting into computer-based database will (probably) not be seen by the people who live 150 years later." This problem is faced for all digital data, and needs to be solved for the whole humankind but is particularly pressing for the science community.

The second section (Digital Atlases of Insect brains) gives first five examples for standard brain atlases (for the locust, the honeybee, two moth species Heliothis and Manduca, and the beetle Tribolium). The last two chapters are concerned about the use of existing brain atlases for specific problems. The first five chapters address the questions of creating and using standard atlases from multiple view points. Should one construct an average atlas from multiple specimens or select a typical individual example? Is the atlas predominantly used for registering single marked neurons or for estimating ontogenetic and evolutionary developments of brain areas? How shall one deal with structural variability at the level of identified neurons or brain areas? These and many more questions are dealt with on the basis of large data sets with respect of the number of brains analyzed, the brain areas studied, and the neurons registered into the respective atlas. Furthermore, recent developments of volume rendering and automatic registration are discussed and evaluated on the basis of experiences with these particular brains. Finally the chapter on the honeybee discusses the use of the standard atlas as a graphical surface and an organizing principle for an ontology of data beyond the structural components. These chapters should be read in connection to recent publications on 
the Drosophila brain (Peng et al., 2010; Shinomiya et al., 2011; Milyaev et al., 2012, see also http://penglab.janelia.org/proj/v3d) since the genetic tools available for Drosophila allowing to mark

\section{REFERENCES}

Chiang, A. S., Lin, C. Y., Chuang, C. C., Chang, H. M., Hsieh, C. H., Yeh, C. W., Shih, C. T., Wu, J. J., Wang, G. T., Chen, Y. C., Wu, C. C., Chen, G. Y., Ching, Y. T., Lee, P. C., Lin, C. Y., Lin, H. H., Wu, C. C., Hsu, H. W., Huang, Y. A., Chen, J. Y., Chiang, H. J., Lu, C. F., Ni, R. F., Yeh, C. Y., and Hwang, J. K. (2011). Threedimensional reconstruction of brainwide wiring networks in Drosophila at single-cell resolution. Curr. Biol.21,1-11.

Hall, D. H., and Russell, R. L. (1991).

The posterior nervous system of the nematode Caenorhabditis elegans: serial reconstruction of identified neurons and complete pattern of synaptic interactions. J. Neurosci. $11,1-22$.

Milyaev, N.,Osumi-Sutherland,D., Reeve, S., Burton, N., Baldock, R. A., and Armstrong, J. D. (2012). The virtual fly brain browser and query interface. Bioinformatics 28, 411-415.

Nusbaum, M. P., and Beenhakker, M. P. (2002). A small-systems approach to motor pattern generation. Nature 417 , 343-350.

types of neurons or even single neurons enhance the power of insect brains as models for the development, use, and maintain standard brain atlases.

Peng, H., Ruan, Z., Long, F., Simpson, J. H., and Myers, E. W. (2010). V3D enables real-time $3 \mathrm{D}$ visualization and quantitative analysis of large-scale biological image data sets. Nat. Biotechnol. $28,348-353$.

Ramon y Cajal, S. (1897). Las leyes de la morfologia y dinamismo de lascelulasnerviosas. Rev. Trim Microgr.

Shinomiya, K., Matsuda, K., Oishi, T. Otsuna, H., and Ito, K. (2011). Fly brain neuron database: a comprehensive database system of the Drosophila brain neurons. J. Comp. Neurol.519, 807-833.
Received: 08 March 2012; accepted: 26 March 2012; published online: 17 April 2012.

Citation: Menzel R (2012) Introduction to the research topic on standard brain atlases. Front. Syst. Neurosci. 6:24. doi: 10.3389/ fnsys.2012.00024

Copyright (ㄷ) 2012 Menzel. This is an openaccess article distributed under the terms of the Creative Commons Attribution Non Commercial License, which permits non-commercial use, distribution, and reproduction in other forums, provided the original authors and source are credited. 